\section{Demeclocycline treatment of water retention in congestive heart failure}

Demeclocycline has been shown to induce nephrogenic diabetes insipidus in normal subjects. ${ }^{1}$ It has been used successfully for treating the syndrome of inappropriate antidiuretic hormone secretion ${ }^{2}{ }^{3}$ and water retention related to liver cirrhosis. ${ }^{4}$ The findings presented here show its efficacy in cardiac oedema unresponsive to classic diuretic treatment.

\section{Patients, methods, and results}

Six patients with chronic congestive heart failure were investigated. Each patient had longstanding overt salt and water retention which had become unresponsive to low salt diet, diuretics, and digitalis treatment. Three patients had overt hyponatraemia. Except for digitalis, which was maintained at the same daily dose, all drugs were withheld throughout the study. The patients were allowed to drink water freely but dietary salt was restricted to $10-20 \mathrm{mmol}(\mathrm{mEq}) /$ day. After five days' bed rest and dietary salt restriction without any change in salt and water retention demeclocycline $(1200 \mathrm{mg} /$ day by mouth) was started.

One patient did not respond to treatment over nine days. The figure shows the results in the other five patients. Progressive weight loss (mean $6.3 \mathrm{~kg}$ ) occurred together with an increase in diuresis (mean $1.67 \mathrm{l} /$ day) and overt salt excretion (mean increase $99 \mathrm{mmol} / \mathrm{day}$ ). The mean urine osmolality of $550 \mathrm{mmol}(\mathrm{mosmol}) / \mathrm{kg} \mathrm{H}_{2} \mathrm{O}$ decreased to $198 \mathrm{mmol} / \mathrm{kg} \mathrm{H}_{2} \mathrm{O}$. Blood urea and creatinine concentrations rose moderately in all patients. Initial hyponatraemia was easily corrected without any significant change in other serum electrolytes. All patients experienced nausea during demeclocycline administration but no other side effects were noted. No glycosuria, proteinuria, or aminoaciduria occurred. Demeclocycline administration was stopped when oedema was clinically undetectable. This was followed by a gradual decrease in diuresis and in salt excretion, and a rise in urine osmolality toward baseline values. The impairment of renal function was completely reversed within 10 days.

\section{Comment}

Demeclocycline is known to inhibit the antidiuretic hormone sensitive medullary adenylcyclase from the kidney, ${ }^{1}$ thus inducing a reversible nephrogenic diabetes insipidus. The drug has been shown to be useful in treating hyponatraemia and water intoxication in patients with inappropriate antidiuretic hormone secretion, ${ }^{23}$ suggesting inhibition of the tubular response to tumoral antidiuretic products.

Demeclocycline has also been successfully used to treat chronic oedema in cirrhotic patients, ${ }^{4}$ inducing substantial increases in urinary water and sodium excretion. An identical effect occurred in our patients with chronic oedema of cardiac origin, suggesting that the antidiuretic hormone is at least partially responsible for the of abnormal water metabolism in liver cirrhosis and heart decompensation. Demeclocycline seems to be very effective in these conditions: in five of our six patients treatment caused the rapid disappearance $\varrho$ of a large fluid accumulation that had not been prevented by classic $\subseteq$ diuretic treatment. Moreover, hyponatraemia was easily controlled $\overrightarrow{\vec{F}}$ in three patients, which suggested that demeclocycline might be especially indicated in hyponatraemic oedematous patients.

Demeclocycline administration substantially increased urinary sodium excretion in our patients; this confirmed the natriuretic effect of the drug, which has been noticed in cirrhotic oedematous patients. ${ }^{4}$ The mechanism of the induced natriuresis is unknown, but an increase in urinary sodium concentration has also been shown to occur in patients with renal insufficiency under tetracycline treat- $\vec{O}$ ment. ${ }^{5}$

The known antianabolic effect of demeclocycline ${ }^{5}$ may partially $\vec{\omega}$ explain the rise in blood urea concentration. In all the patients studied there was also a moderate rise in blood creatinine concentration. Hypovolaemia probably does not explain the reversible impairment of renal function since the only patient who did not respond to DMC o by water and sodium excretion also showed an increase in blood $\vec{A}$ creatinine concentration. A drug-related nephrotoxicity must there- $\vec{G}$ fore be postulated. Regular monitoring of renal function is required $\partial$ during demeclocycline treatment and the drug is probably contraindicated in patients with baseline azotaemia. Nevertheless, the beneficial effects of this treatment probably outweigh its drawbacks.

${ }^{1}$ Singer, I, and Rotenberg, D, Annals of Internal Medicine, 1973, 79, 679. 2 De Troyer, A, and Demanet, J C, New England Fournal of Medicine, 1975, 293, 915.

${ }^{3}$ De Troyer, A, Fournal of the American Medical Association, 1977, 237, 2723.

${ }^{4}$ De Troyer, A, Zegers de Beyl, D, and Demanet, J C, Kidney International, $1977,11,289$.

5 Shils, M E, Annals of Internal Medicine, 1963, 58, 389.

(Accepted 10 November 1977)

Department of Internal Medicine, Saint Pierre Hospital, Brussels School of Medicine, Brussels, Belgium

D ZEGERS DE BEYL, MD, assistant

R NAEIJE, MD, assistant

A DE TROYER, MD, assistant
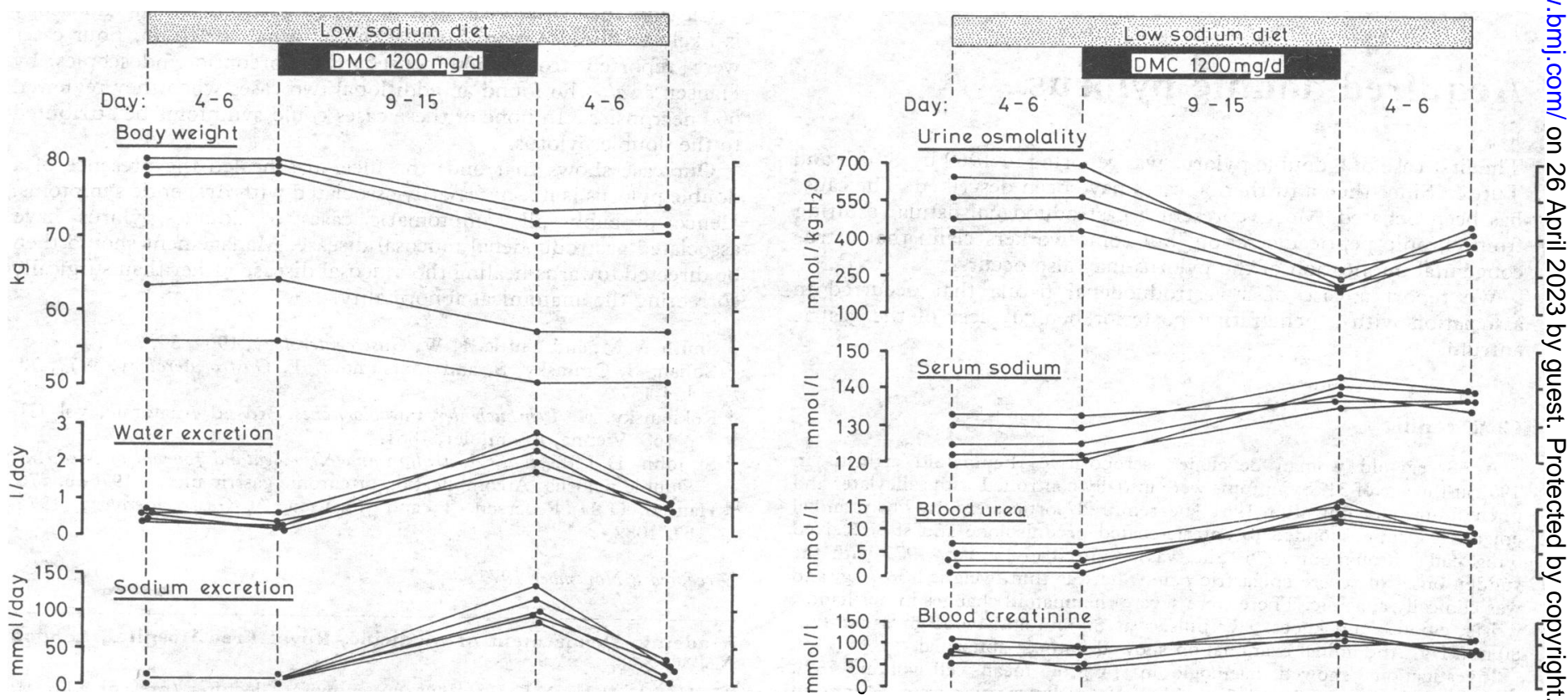

Changes in weight, water and sodium excretion, serum sodium, urine osmolality, and blood urea and creatinine concentrations before, during, and after demeclocycline (DMC) treatment $(1200 \mathrm{mg} /$ day $)$ in five patients with congestive heart failure and oedema.

Conversion: SI to traditional units-Sodium: $1 \mathrm{mmol}=1 \mathrm{mEq}$. Osmolality: $1 \mathrm{mmol} / \mathrm{kg} \mathrm{H}_{2} \mathrm{O}=1 \mathrm{mosmol} / \mathrm{kg} \mathrm{H} \mathrm{H}_{2} \mathrm{O}$. Urea: $1 \mathrm{mmol} / 1 \approx 6 \mathrm{mg} / 100 \mathrm{ml}$. Creatinine : $1 \mu \mathrm{mol} / 1 \approx 0.0113 \mathrm{mg} / 100 \mathrm{ml}$. 